\title{
Aerobic Rice Production System(ARPS): Improving Productivity and Profitability in Water-Scarce Areas of Bulacan
}

\author{
Dinah Marie C. Dayag', Junel B. Soriano², Josie A. Valdez ${ }^{1}$, and \\ Gregory Moses Villacorta ${ }^{1}$
}

${ }^{1}$ Bulacan Agricultural State College, Pinaod, San Ildefonso, Bulacan

${ }^{2}$ ICRISAT, Pantencheru, India

\begin{abstract}
On-farm study on rice-based cropping system following recent water-saving technologies for rice production such as ARPS-ARPS, ARPS-alternate wetting and drying (AWD) and existing or Farmers' Practice (FP) was conducted in a rainfed lowland area in Brgy. Mataas na Parang, San Ildefonso, Bulacan. Field experiments were conducted from June to November 2011 for the wet season and December 2011 to March 2012 for the dry season. Variety used for the ARPS and AWD was NSIc Rc192 and PSB Rc18 for FP. Yield and yield components of the three treatments showed no significant difference during WS. Significant higher number of tillers hill ${ }^{-1}$ was observed for ARPS-ARPS and ARPS-AWD compared to FP. No significant difference was observed for the yield and yield components during the dry season (DS) for ARPS-ARPS and ARPS-AWD. FP was not established during the DS because of the unavailability of water during the time. During WS, ARPS was the most appropriate cropping system since this intervention obtained higher water productivity and ROI when compared with the FP. During the dry season, AWD and ARPS were suitable to the rainfed lowland areas of Bulacan. Results of this study showed that aerobic rice production system for the rainfed lowland areas improved water and land productivity as well as increased annual rice production and farmers' income most particularly in ARPS-AWD which consistently gave the highest net income of PhP 36,896.20, PhP14,417.50 and PhP51,313.70 during the Wet Season, Dry Season and for the total two cropping seasons, respectively
\end{abstract}

Keywords: Aerobic rice production system, alternate wetting and drying, farmer's practice, water productivity, cropping system, rice ecosystems

Correspondence : D.M.C. Dayag Address: Bulacan Agricultural State College, Pinaod, San Ildefonso, Bulacan E-mail: dina_cabiles@yahoo.com Tel: 09175270811 Fax: (044) 6772264

DOI: $10.32945 /$ atr3629.2014 
Improving Productivity and Profitability in Water-Scarce Areas of Bulacan

\section{INTRODUCTION}

The disturbing crisis on water shortage and abnormal occurrence of rainfall in relation to crop production particularly rice, is getting bad as climate is continuously changing and population continuously grows. With the declining and limited water available for rice production, there is a need to adopt water-saving measures for rice production in order to conquer the challenge of feeding people living and relying on rice.

In water-scarce areas of Luzon, rice farmers produce rice normally for one cropping season (wet season) using the usual practice of growing transplanted rice. Most areas, therefore, remain idle for the succeeding months. However, some are planted with vegetables and rice especially those areas with supplementary irrigation system (e.g. small water impounding and shallow tube well). Irrigated rice land represents about $43.87 \%$ and $56.13 \%$ (rainfed) of the total potential irrigable area. The average cropping intensity in irrigated rice lands is around $175 \%$ and only $100 \%$ in rainfed areas. It indicates that though there are developed irrigation systems, some of the potential service areas still remain uncropped. This is due to the limited water resource saved during rainy days. Average yield of rice in rainfed areas is $3.56 \mathrm{t} \mathrm{ha}^{-1}$. This project addressed issue on how to increase rice production in whole year-round with the limited water resource as major factor affecting rice production in rainfed areas.

Promising technologies for rice production nowadays are aerobic rice technology, and controlled irrigation). Aerobic rice technology involves the growing of an aerobic rice variety in non-flooded and non-puddled soil using supplementary irrigation. In Bulacan experience, aerobic rice system gain an average yield of $4.5 \mathrm{tha}^{-1}$ during wet season and $3.5 \mathrm{tha}^{-1}$ in the dry season.

Results of the different experiments conducted in the province of Bulacan on aerobic rice, suggests that this new rice production system must be explored further especially in rainfed areas where water is limited and fragmented throughout the year. In addition, management practices of aerobic rice technology during wet season are seen to be the best alternative in terms of rice production in the rainfed areas. Farmers and researchers noted a number of advantages of aerobic rice technology over the conventional rice farming methods. Among these advantages are: (1) low input requirement; (2) crop manageability; (3) yield competitiveness; (4) profitability; (5) early establishment which enhances water and land 
Dayag et al.

productivity; (6) resistance to pests and diseases; and (7) weed competitiveness. With the identified potentials and benefits, efforts must be exerted to further develop, promote and disseminate the technology in the rainfed areas while gearing toward more comprehensive research activities to fine-tune specific management practices for the technology especially during the dry season (Soriano, et al., 2005).

One way of increasing cropping intensity in rainfed areas is through improving the cropping systems. This may include cultivating rainfed lands twice, proper scheduling of cropping calendar to optimize the use of available water, imposing water-saving technologies for rice production and growing crops not susceptible to water stress such as aerobic rice (Bouman, 2001; Bouman, etal., 2005).

Improved rice-based cropping system through appropriate rice production technologies will increase water and land productivity as well as income of the farmers in the rainfed areas. After validation through demonstration of appropriate cropping system in selected provinces of Luzon, such methodologies and significant results will be disseminated to other regions of the country experiencing the same situations and fragile ecosystems in terms of food production.

The project generally aims to improve rice-based cropping system through appropriate water-saving technologies and water resource management for improved water, land and labor productivity, increased rice production and farmers' income through the conduct on-farm study on cropping systems following recent water-saving technologies on rice production using drought resistant rice variety in a lowland rainfed areas of Bulacan.

\section{MATERIALS AND METHODS}

Establishment of on-farm study on cropping system following recent water-saving technologies for rice production served as treatments. The treatments were as follows : a. Aerobic Rice Production System - Aerobic Rice Production System (ARPS-ARPS), b. Aerobic Rice System Alternate Wet and Dry (ARSP-AWD), and c. Existing or Farmer's Practice (FP);

Rainfall data in the site were collected and analysed before the conduct of the study in order to establish the most appropriate cropping pattern and prepared an accurate calendar of the experiment. Data analysis was done using computer softwares and programs. Developed cropping pattern and calendar were evaluated before the field testing in terms of 
Improving Productivity and Profitability in Water-Scarce Areas of Bulacan

economics, technical feasibility, management and farmers acceptability. This was done two months prior to the start of the experiment.

Field experiments were established from June-November 2011 for the first crop cropping following ARPS and December 2011 to March 2012 for the second cropping season. The variety used for treatments 1 and 2 was NSIC Rc 192 while PSB Rc18 for FP.

The field experiments were arranged in Randomized Complete Block Design (RCBD) with three replications. The size of the experimental plots for the three farming systems is $6 \mathrm{~m} \times 8 \mathrm{~m}$. For ARS both in dry and wet season, the rice fields were prepared with two times plowing, harrowing and land leveling thereafter. Seeding was done manually in rows $30 \mathrm{~cm}$ apart. Seeds were manually distributed and covered with soil $3.0 \mathrm{~cm}$ deep at seeding rate of $80 \mathrm{~kg} \mathrm{ha}^{-1}$. After seeding, flush irrigation of about $3 \mathrm{~cm}$ depth was done. For weed and insecticides control, the usual practice of farmers using weedicides and insecticides were adopted.

Agronomic data such as weekly plant height $(\mathrm{cm})$ and weekly tiller count of the rice crop were monitored and recorded. Grain yield were taken from a 6- $\mathrm{m}^{2}$ area in the center of each plot and expressed in $\mathrm{t} \mathrm{ha}^{-1}$ at 14\% moisture. Yield components gathered includes tiller number per linear meter, panicle number per linear meter, spikelets number per panicle, percent filled spikelets and 1,000-grain weight. Two sampling rows of $0.5 \mathrm{~m}$ length were designated in all plots for the determination of yield components.

After the first cropping, the land was prepared for planting just after harvest. Plowing was done while there was still available standing water from rain. This is to optimize the use of the available water/moisture in the experimental area. The same treatments were used. The treatment for ARPS and AWD were established . Farmer's practice was not established since during that time, no enough water was available for the establishment. The agronomic data parameters collected from the rice plants on the second cropping were the same from those collected from the first cropping.

Analysis of variance (ANOVA) and comparison of treatment means using DMRT at 5\% level of significance and T-test were done using the Sirichai Statistics Version 6.07. Built-in functions under Excel Windows Program was used to compute, organize and plot the data.

Water inputs (irrigation + rainfall) were recorded separately in all cropping system plots. Cost and return of production was likewise recorded and computed to evaluate the economics of the different farming 


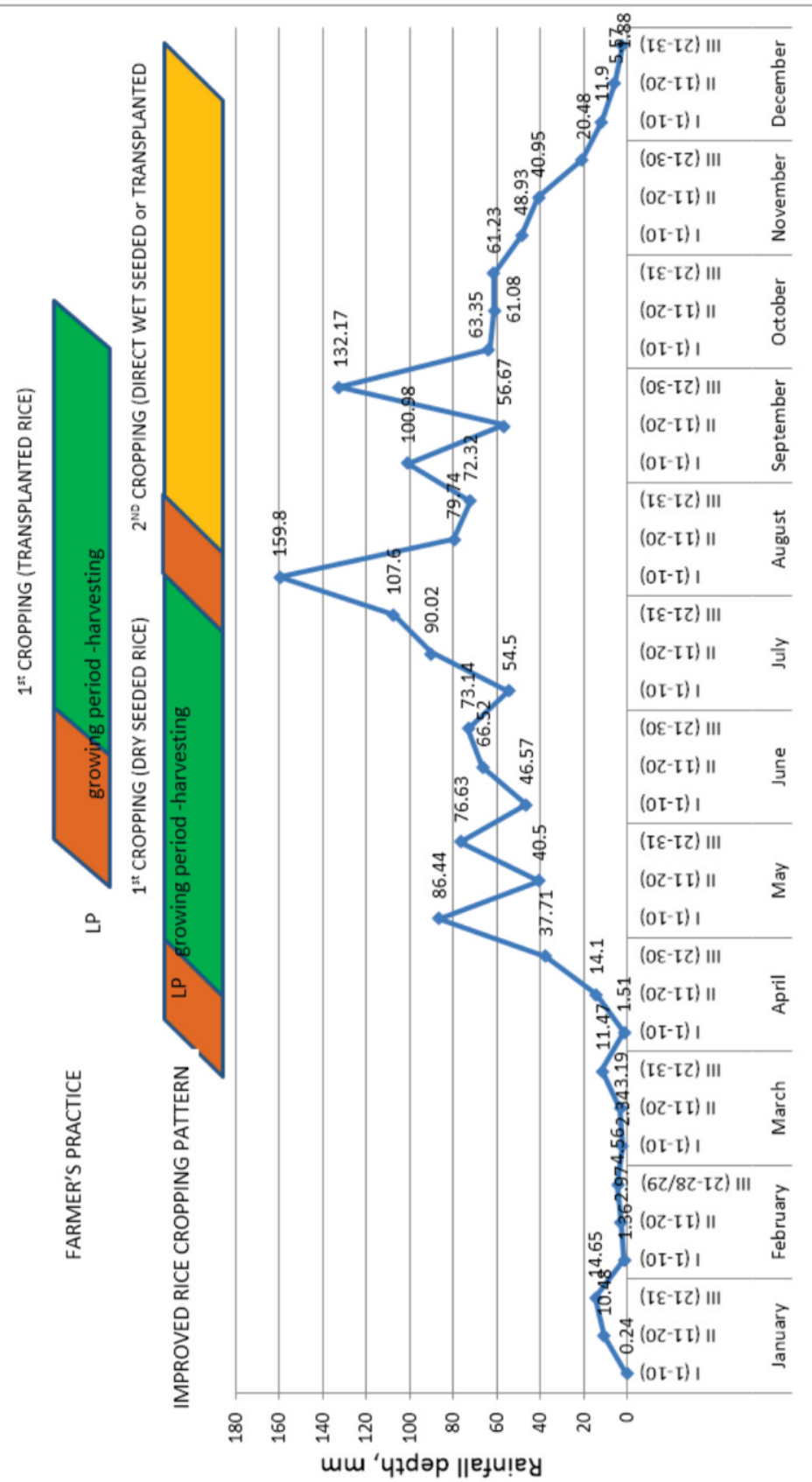

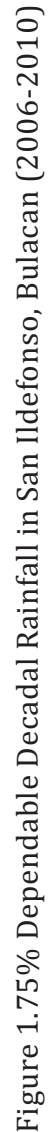


Improving Productivity and Profitability in Water-Scarce Areas of Bulacan

systems. Land productivity was determined using cropping intensity as indicator. Cropping intensity was computed by using the formula given below:

Cropping intensity $=($ Gross cropped area $/$ Net sown area $) \times 100$

\section{RESULTS AND DISCUSSION}

\section{Rainfall Characteristics of San Ildefonso, Bulacan}

Rainfall is the primary source of irrigation water for rice crops in rainfed areas. The variability of its amount and distribution affects rice production and yield. To maximize the use of rainfall for irrigation, rice should be planted in proper sequence or in combination with other crops in accordance with the rainfall pattern and condition of a certain locality. In line with this, a probability distribution of rainfall amount was prepared. This was developed from existing climate data to provide information on the length of the rainy season and the amount of water available during each stage of the growing season. With this information, farmers will be able to plan the use of improved crop rotation, better crop varieties, and improved farming operations.

Figure 1 reflected the three rice cropping patterns- the farmer's practice and the improved rice cropping patterns for the rainfed lowland areas in the site. The figure showed that the possibility of planting two rice crops in sequence is high provided that the first crop was sown directly (dry seeding) prior to the onset of rainy season using early maturing and lodging resistant varieties. For the second cropping, direct wet seeded rice farming system using early maturing and drought tolerant varieties can be adopted. In this option, preparing the land right after the harvest of the first crop was done to maximize the use of available moisture in the soil.

\section{Yield and Yield Components}

No significant difference was observed for \% filled grains, weight of 1000 grains and yield during the wet season. However, significant higher number of tillers/hill was observed in ARPS-AWD and ARPS-ARPS compared with the FP (farmer's practice).

During dry seasons, no significant difference was also observed for the yield and yield components among the treatments used. Farmer's practice 
was not established since harvest during the first cropping season was late and there was not enough water for planting the FP (Table 1).

Table 1. Agronomic, yield and yield component parameters of rice under the different cropping systems for wet season, dry season and its total two cropping seasons in rainfed lowland areas of Bulacan

\begin{tabular}{|c|c|c|c|c|}
\hline $4 \leq^{\circ} \# \cdot 1 \unrhd$ & $\begin{array}{l}\text { Weight of } 1000 \\
\text { Grains }(\mathrm{g})\end{array}$ & $\begin{array}{l}\text { No. of Tillers } \\
\text { hill }^{-1}\end{array}$ & $\begin{array}{c}\text { Filled } \\
\text { Grains (\%) }\end{array}$ & Yield (tons ha-1) \\
\hline \multicolumn{5}{|l|}{ Wet season (WS) } \\
\hline ARPS-ARPS & $24.13 \mathrm{a}$ & $54 a$ & $75.21 \mathrm{a}_{\mathrm{a}}$ & $4.16_{a}$ \\
\hline ARPS-AWD & $23.53 \mathrm{a}$ & 56 a & $76.51_{a}$ & $4.46_{a}$ \\
\hline FP & $26.95 \mathrm{a}$ & $47 \mathrm{~b}$ & $76.86_{a}$ & $4.74 a$ \\
\hline \multicolumn{5}{|l|}{ Dry season (D) } \\
\hline ARPS-ARPS & $27.00_{\mathrm{a}}$ & $59 \mathrm{a}$ & $75.75_{a}$ & $2.74 a$ \\
\hline ARPS-AWD & $26.00_{a}$ & $62 \mathrm{a}$ & $78.85 \mathrm{a}$ & $3.00_{\mathrm{a}}$ \\
\hline FP & - & - & - & - \\
\hline
\end{tabular}

\section{Water Productivity}

Total water input was computed by adding the amount of rainfall during the duration of cropping from land preparation to harvesting. All treatments received no irrigation water since it was tested in a purely rainfed area during the wet season. ARPS-ARPS and ARPS-AWD treatments were established in dry on May 25 before the onset of the rainy season and soil and harvested on September 6, 2011 which received a total rainfall of 1.23 $\mathrm{m}$. This difference can be attributed to several factors like different timing and system of crop establishment and different rainfall depth received during the duration of the cropping. On the other hand, the FP treatment was established on June 21 and harvested on November 12, 2011 receiving a total rainfall depth of $1.73 \mathrm{~m}$. The FP during DS was not established due to unavailability of enough moisture.

Among the different treatments, water productivity (WP) was highest in ARPS-AWD followed by ARPS-ARPS treatment with WP of 0.36 and 0.33 $\mathrm{kg}$ of grains $\mathrm{m}^{-3}$ during the wet season. During dry season, WP was higher in ARPS-ARPS compared with ARPS-AWD. Higher water productivity means more grains produced for every cubic meter of water consumed by the rice plants (Table 2).

Land Use and Productivity

Originally, the farmer's practice cropping is once per year using the traditional system of cultivation (transplanted and flooded irrigation 
Improving Productivity and Profitability in Water-Scarce Areas of Bulacan

system). After the wet season, the residual moisture available in the field was able to sustain the water requirement for aerobic rice production and alternate wetting-and-drying. As a result, the farmer was able to achieve $200 \%$ cropping intensity since he was able to double his cropping intensity due to the availability of agricultural inputs.

Table 2. Water Productivity (WP) of rice under the different cropping systems during the Wet Season, Dry Season and its total two cropping seasons in the Rainfed lowland areas of Bulacan.

\begin{tabular}{|c|c|c|c|c|c|}
\hline & $4 \varrho^{\circ} ¥ \bullet \not \amalg$ & $\begin{array}{l}\text { Total Water } \\
\text { Input }(\mathrm{m})\end{array}$ & $\begin{array}{c}\text { Vol. water/ha } \\
\left(\mathrm{m}^{3}\right)\end{array}$ & $\begin{array}{c}\text { Grain Yield } \\
\left(\mathrm{kg} \mathrm{ha}^{-1}\right)\end{array}$ & $\begin{array}{c}\text { WP } \\
\left(\text { kg grains m }^{-3}\right)\end{array}$ \\
\hline \multicolumn{6}{|l|}{ WS } \\
\hline & ARPS-ARPS & 1.23 & 12,300 & 4157 & 0.33 \\
\hline & ARPS-AWD & 1.23 & 12,300 & 4463 & 0.36 \\
\hline & FP & 1.73 & 15,300 & 4740 & 0.31 \\
\hline \multicolumn{6}{|l|}{ DS } \\
\hline & ARPS-ARPS & 0.41 & 4100 & 2740 & 0.67 \\
\hline & ARPS-AWD & 0.54 & 5368 & 3005 & 0.56 \\
\hline & FP & --- & --- & --- & \\
\hline
\end{tabular}

\section{Cost and Return Analysis}

The introduced technology production system (ARPS-ARPS and ARPS-AWD) resulted in higher ROI which can be attributed to the savings from water and labor utilized in the different cropping systems during wet and dry cropping seasons. During WS, the highest return of investment was achieved using the ARPS-AWD followed by ARPS-ARPS with ROI of $107.0 \%$ and $103.1 \%$, respectively. Farmer's practice had the lowest ROI. During the DS, high ROI was achieved following the ARPS-AWD with a ROI of $42.9 \%$ and ARPS-ARPS with $40.5 \%$ (Table 3 ).

\section{CONCLUSION}

No significant difference in yield was observed for the three treatments. However, water productivity is higher in ARPS-AWD plots by $14 \%$ compared with the FP plot.

The early establishment of ARPS treatments allowed earlier harvest of the crops. The residual moisture during the first cropping allowed the establishment of another cropping for rice which is not usually practiced by the farmer. Farmer's practice was not established during DS because of the unavailability of water. 
During wet season, ARPS is most appropriate cropping system due to high ROI. During the dry season, AWD and ARPS are suitable to the lowland rainfed area of Bulacan. Establishment of these two cropping systems can increase cropping intensity, water productivity and income of farmers.

Table 3 . Cost and Return Analysis for 1 hectare using ARPS, AWD and FP during wet and dry seasons.

\begin{tabular}{lccc}
\hline & ARPS-ARPS & ARPS-AWD & FP \\
\hline Wet-Cropping Season & 4.16 & 4.46 & 4.74 \\
Yield, t/ha & $66,560.00$ & $71,360.00$ & $75,840.00$ \\
Gross income, PhP & $32,768.20$ & $34,463.80$ & $40,645.80$ \\
Total Cost of Production & $33,791.80$ & $36,896.20$ & $35,194.20$ \\
Net Income & 103.1 & 107.0 & 86.6 \\
ROI & & & \\
Dry-Cropping Season & 2.74 & 3.0 & --- \\
Yield, t/ha & $43,840.00$ & $48,000.00$ & --- \\
Gross income, PhP & $31,197.80$ & $33,582.50$ & --- \\
Total Cost of Production & $12,642.20$ & $14,417.50$ & --- \\
Net Income & 40.5 & 42.9 & --- \\
ROI & & & \\
\hline
\end{tabular}

\section{ACKNOWLEDGEMENT}

The proponents of this research project wishes to express gratitude to the following groups and individuals.

To the Commission on Higher Education Zonal Research Center Region III \& Central Luzon State University Program Cluster Implementers (CHED ZRC III - CLSU PCI) headed by its Director, Dr. Renato G. Reyes of CLSU who considered this project for funding. Aside form the financial requirements that the Center is providing, we also acknowledge their efforts in giving technical and administrative assistance as to how this project will be implemented efficiently.

To the farmer-cooperator who provided parcel of his land which was used as field experiments and their involvement especially on data gathering and other related farming activities.

To the BASC administrative staff headed by the College President, Dr. Gerardo I. Mendoza for delivering services related on administration and financial management. 
Improving Productivity and Profitability in Water-Scarce Areas of Bulacan

\section{REFERENCES}

BOUMAN, B.A.M. 2001. Water-efficient management in rice production. Int. Rice Res.Notes 26(2), 17-22

BOUMAN, B.A.M., T.P. TUONG. 2001. Field water management to save water and increase its productivity in irrigated lowland rice. Agri.Water Management, 49:11-30

SORIANO, J. B., B.A.BOUMAN, R.M.LAMPAYAN, J.A.VALDEZ, L.B.SILVERIO, B.V.VILLANUEVA, W.PERALTA, M.I.PASTRANA, J.P.MENDOZA, R. MAGBUANA, L. CARAMIHAN, 2005. Aerobic Rice System in Rainfed Areas of Bulacan - R \& D Project. 